Jurnal Abdidas Volume 1 Nomor 4 Tahun 2020 Halaman 254 - 260
JURNAL ABDIDAS

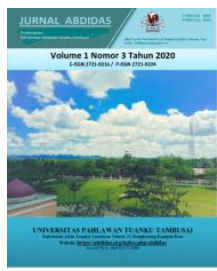

\title{
Penyuluhan Personal Higyene pada Lanjut Usia di UPT Pelayanan Sosial Tresna Werdha Husnul Khotimah Kota Pekanbaru
}

\author{
Herniwanti $^{1}$, Jasrida Yunita ${ }^{2}$, Endang Purnawati Rahayu ${ }^{3}$ Kiswanto $^{4}$ \\ STIKes Hang Tuah Pekanbaru, Riau, Indonesia 1,2,3,4 \\ E-mail : herniwanti_h@yahoo.com ${ }^{1}$ jasridayunita@gmail.com ${ }^{2}$ endangpurnawati90@gmail.com ${ }^{3}$ \\ kiswanto@gmail.com ${ }^{4}$
}

\begin{abstract}
Abstrak
Pengabdian masyarakat yang dilaksanakan oleh tim dosen Stikes Hang Tuah Pekanbaru di UPT Pelayanan Sosial Tresna Werdha Husnul Khotimah Kota Pekanbaru pada bulan Januari 2020 adalah untuk memberikan penyuluhan mengenai Kesehatan Lansia dengan tema "Upaya Promotif dan Preventif dalam mengatasi permasalahan Gizi, Hipertensi, Persona Hyigene dan Peningkatan Active Aging pada Lanjut Usia". Metode yang digunakan adalah dengan penyuluhan dan mengajak lansia untuk memahami persoal hyigene walaupun di Panti Werda disediakan perawat untuk membantu dan menjaga kebersihan lansia tapi kesadaran sendiri tetap diperlukan untuk mencegah penyakit, dan juga dicontohkan dan dipraktekkan cara mencuci tangan yang baik dengan lima langkah. Jumlah lansia disana ada sekitar 69 orang dan yang hadir dia acara penyuluhan 30 orang yang aktif terdiri dari lansia perempuan 30 orang dan laki-laki 10 orang, yang lainnya tidak bisa hadir karena perlu perawatan dikamar. Perhatian pemerintah cukup baik pada Panti Werda ini dilihat dari kehidupan yang sejahtera serta sarana dan prasarana yang lengkap dan bersih serta petugas yang cukup untuk memberikan perhatian kepada lansia. Walaupun setiap minggunya ada pengecekan oleh dokter dan juga banyak para donator yang datang memberikan bantuan sembako dan suvenir lainnya untuk menghibur lansia dan perawat disana, dari hasil penyuluhan diketahui bahwa lansia sangat bersemangat dan bergembira mengikuti penyuluhan dan berharap bisa dilaksanakan secara berkala sebagai bentuk perhatian dan pengabdian masyarakat dalam bidang kesehatan kepada pada lansia dan pelaksanaan tridarma perguruan tinggi dari kampus kesehatan dalam bentuk nyata.
\end{abstract}

Kata kunci: penyuluhan, personal hygiene, lansia

\begin{abstract}
The community service carried out by the lecturer team of Stikes Hang Tuah Pekanbaru at the Tresna Werdha Husnul Khotimah Social Service Unit in Pekanbaru City in January 2020 is to provide counseling on the Health of the Elderly with the theme "Promotional and Preventive Efforts in Overcoming Nutritional Problems, Hypertension Persona Hygiene and Active Improvement. Aging in the elderly". The method used is counseling and inviting the elderly to understand the problem of hygiene, even though nurses are provided at the Werda Home to help and maintain the cleanliness of the elderly but awareness is still needed to prevent disease. and also demonstrated and practiced how to wash hands properly in five steps. The number of elderlies there were around 69 people and those who attended the counseling event were 30 people who were active consisting of 30 elderly women and 10 men, others could not attend because they needed treatment in the room. The government's attention is quite good at this Werda Home seen from a prosperous life as well as complete and clean facilities and infrastructure as well as adequate staff to give attention to the elderly. Even though every week there are checks by doctors and also many donors who come to provide basic food assistance and other souvenirs to entertain the elderly and nurses there, from the results of the counseling it is known that the elderly are very excited and happy to participate in counseling and hope it can be carried out regularly as a form of attention and dedication. community in the health sector to the elderly and the implementation of the tridarma of higher education from the health campus in real form
\end{abstract}

Keywords: counseling, personal hygiene, elderly people

Copyright (c) 2020 Herniwanti, Jasrida Yunita, Endang Purnawati Rahayu, Kiswanto

$\triangle$ Corresponding author:

Address : Jln.Paus Ujung No.5, Marpoyan Damai Pekanbaru

Email : Herniwanti_h@yahoo.com

Phone : 082156553120

ISSN 2721- 9224 (Media Cetak)

ISSN 2721- 9216 (Media Online)

DOI : https://doi.org/10.31004/abdidas.v1i4.55 


\section{PENDAHULUAN}

Undang-undang Nomor 13 tahun 1998 tentang Kesejahteraan Lansia menyatakan bahwa yang dimaksud dengan Lansia adalah penduduk yang telah mencapai usia 60 tahun ke atas yang juga mempunyai hak yang sama untuk mendapatkan pelayanan kesehatan. Kelompok ini merupakan penduduk yang tergolong rentan, yang sering dianggap menjadi beban bagi kelompok penduduk lainnya (Permenkes RI No.25, 2016).

Menurut hasil dari Susenas jumlah Lanjut Usia (Lansia) 14,4 juta jiwa atau 7,18\% dari total jumlah penduduk, sedangkan yang berusia di atas 65 tahun, mencapai 4,6\% dari jumlah penduduk Indonesia (10 juta orang). Selain itu, jumlah lansia diproyeksikan akan terus meningkat yang diperkirakan pada tahun 2020 diperkirakan meningkat menjadi 28,8 juta jiwa (Badan Pusat Statistik et al., 2013).

Keberadaan lansia seringkali dipersepsikan secara negatif, dianggap sebagai beban keluarga dan masyarakat sekitarnya serta dianggap sebagai individu yang tidak mandiri. Kenyataan ini mendorong semakin berkembangnya anggapan bahwa menjadi tua identik dengan semakin banyaknya masalah yang dialami oleh lansia. Lansia cenderung dipandang masyarakat tidak lebih dari sekelompok orang yang ketergantungan dengan orang-orang yang ada disekitarnya (Huda, 2004).

Perubahan fisik yang terjadi pada lansia erat kaitannya dengan perubahan psikososialnya. Pengaruh yang muncul akibat berbagai perubahan pada lansia tersebut jika tidak teratasi dengan baik, cenderung akan mempengaruhi kesehatan lansia secara menyeluruh (Yuliati et al., 2014).

Pada kurun waktu 10 tahun terakhir terjadi peningkatan populasi lansia di Indonesia. Hal ini meningkatkan besarnya permasalahan lansia khususnya masalah gizi dan kesehatan karena terjadi peningkatan penyakit degeneratif utamanya penyakit jantung koroner, hipertensi, dan diabetes mellitus. Hal ini dipicu oleh bertambahnya jumlah lansia yang mengalami obesitas, di samping juga masih bermunculan kasus-kasus gizi kurang dan penyakit infeksi seperti anemia (Fatimah, 2012).

Upaya peningkatan kesehatan lansia dengan penyakit kronis adalah melalui peningkatan gaya hidup sehat sehari-hari. Gaya hidup sehat yang harus diterapkan oleh lansia dengan penyakit kronis adalah: melakukan beberapa program latihan atau olah raga secara rutin, diet yang sehat (retriksi asupan garam, lemak ataupun kolesterol), menghentikan kebiasaan merokok, menghindari minuman beralkohol dan mengandung kafein, menghindari stress emosional, dan control kesehatan secara rutin minimal setiap bulannya (Zulfitri, 2011).

Berdasarkan observasi awal yang dilakukan bahwa kondisi lanjut usia di UPT Pelayanan Sosial Tresna Werdha Husnul Khotimah Kota Pekanbaru bahwa banyaknya aktivitas yang dilakukan sehingga lanjut usia harus dalam kondisi sehat untuk mengikuti semua kegiatan tersebut. Dengan ini, maka perlu dilaksanakan peningkatan pengetahuan dan pencegahan kesehatan lanjut yang diharapkan dapat membantu dan memberi manfaat bagi masyarakat. Untuk itu upaya yang dilakukan misalnya dengan memperhatikan asupan 
gizi pada lanjut usia, penyakit hipertensi pada lanjut usia, personal hygiene pada lanjut usia dan dengan memberikan olahraga misalnya senam lansia untuk para lansia.

personal hygiene lansia sangat dipengaruhi oleh beberapa faktor faktor yang ditentukan oleh keadaan masa lalu, situasi lingkungan, lingkungan dimana kita tinggal serta faktor-faktor pribadi. Lansia perlu mendapatkan perhatian dengan mengupayakan agar mereka tidak terlalu tergantung kepada orang lain dan mampu mengurus diri sendiri (mandiri), menjaga kesehatan diri.

Penyuluhan personal hygiene pada lansia di UPT Pelayanan Sosial Tresna Werdha Husnul Khotimah Kota Pekanbaru diharapkan dapat memberikan penyuluhan kesehatan lingkungan kepada masyarakat pada umumnya dan lansia khususnya mengenai mengubah perilaku dan persepsi lanjut usia mengenai personal hygiene dan menambah wawasan mengenai personal hygiene lanjut usia sehingga dapat meningkatkan status kesehatan pada lanjut usia di UPT Pelayanan Sosial Tresna Werdha Husnul Khotimah Kota Pekanbaru.

\section{METODE}

Kegiatan pengabdian kepada masyarakat ini dilakukan dengan bekerjasama dengan Puskesmas Simpang Tiga. Metode yang dilakukan adalah dengan pemberian pendidikan masyarakat dengan penyuluhan mengenai personal hygiene pada lanjut usia dengan melakukan penyuluhan, pemutaran video, dan praktek cuci tangan sampai bersih dengan 5 langkah pada lanjut usia.
Lokasi kegiatan pengabdian masyarakat dilakukan di UPT Pelayanan Sosial Tresna Werdha Husnul Khotimah Kota pada tanggal 23 Januari 2020. Sasaran pengabdian kepada masyarakat adalah sebanyak 69 orang lanjut usia yang berada di UPT Pelayanan Sosial Tresna Werdha Husnul Khotimah Kota Pekanbaru.

Metode pendidikan masyarakat yang dilakukan dimulai dari tahap persiapan, pelaksanaan dan evaluasi sebagai berikut:

1. Tahap persiapan : bekerjasama dengan Puskesmas Simpang Tiga Pekanbaru untuk pelaksanaan pengabdian masyarakat karena panti werda ini dibawah binaan mereka.

2. Tahap pelaksanaan: metode yang dilakukan dengan melakukan penyuluhan dengan ceramah dan pemutaran video mengenai personal hygiene pada lansia.

3. Tahap observasi: observasi dilakukan untuk mengetahui pengetahuan lansia terhadap materi yang telah disampaikan dengan melakukan tanya jawab secara lisan mengenai pemahaman personal hygiene lansia dan observasi langsung setelah kegiatan dilaksanakan.

\section{HASIL DAN PEMBAHASAN}

Pengabdian masyarakat dengan penyuluhan personal higyene pada lanjut usia di UPT Pelayanan Sosial Tresna Werdha Husnul Khotimah Kota Pekanbaru menghasilkan sambutan yang baik oleh pihak yayasan dan juga penghuni lansia yang berada di tempat tersebut. Tema yang dibawa adalah "Upaya Promotif dan Preventif dalam mengatasi permasalahan Gizi, 
Hipertens, Persona Hyigene dan Peningkatan Active Aging pada Lanjut Usia”.

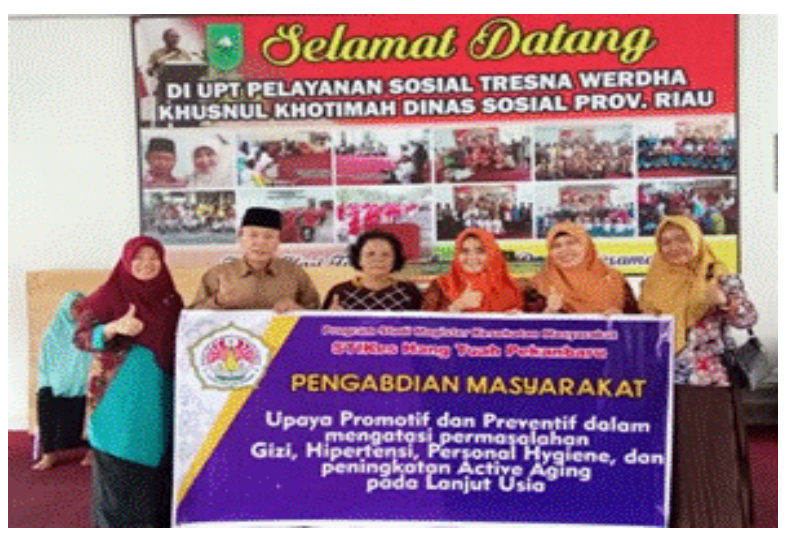

Gambar 1 : Foto Bersama pengurus UPT Pelayanan Sosial Tresna Werdha Husnul Khotimah Kota Pekanbaru.

Jumlah peserta yang hadir adalah sebanyak 40 orang lansia dengan 30 orang peserta wanita dan 10 orang pria. Memang peserta wanita lebih banyak dibandingkan dengan laki-laki di panti werda ini. Acara dimulai dengan perkenalan, pembagian makanan ringan (susu, buah, kue) dan juga simulasi dan door prize untuk lansia yang aktif.

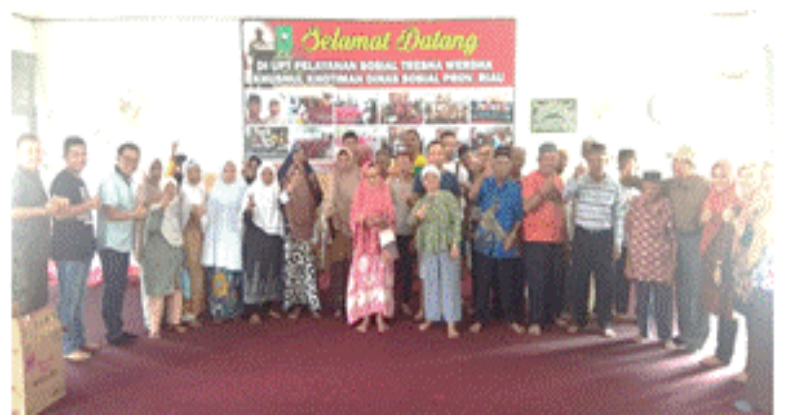

Gambar 2 : Foto Bersama Dosen Magister STIKes Hang Tuah Pekanbaru dan Lansia di UPT Pelayanan Sosial Tresna Werdha Husnul Khotimah Kota Pekanbaru.

Dengan adanya penyuluhan ini diharapkan adanya perubahan perilaku lansia hidup sehat dan bersih dan menjaga kebersihan pribadi menjadi sebuah perilaku yang lebih baik, senada dengan hasil penelitian yang menyatakan sangat penting menjaga perilaku hidup sehat (PHBS) dan bermanfaat untuk mencegah penyakit, kesejahteraan dan kualitas hidup lansia.

Dalam pengabdian bisa dilihat bawah kesadaran menjaga kebersihan pribadi pada lansia dipengaruhi oleh karakteristik lansia, seperti usia, pendidikan, pekerjaan, kepemilihan media yang mendukung keterpaparan dengan informasi seputar personal hygiene serta status tinggal bersama keluarga. Sesuai dengan penelitian yang menyatakan perbedaan jenis kelamin turut berpengaruh dalam dalam PHBS, lansia yang berpendidikan SMP/SMA serta mempunyai pekerjaan (pedagang dan petani) berada dalam kategori PHBS baik (Firmana, 2016).

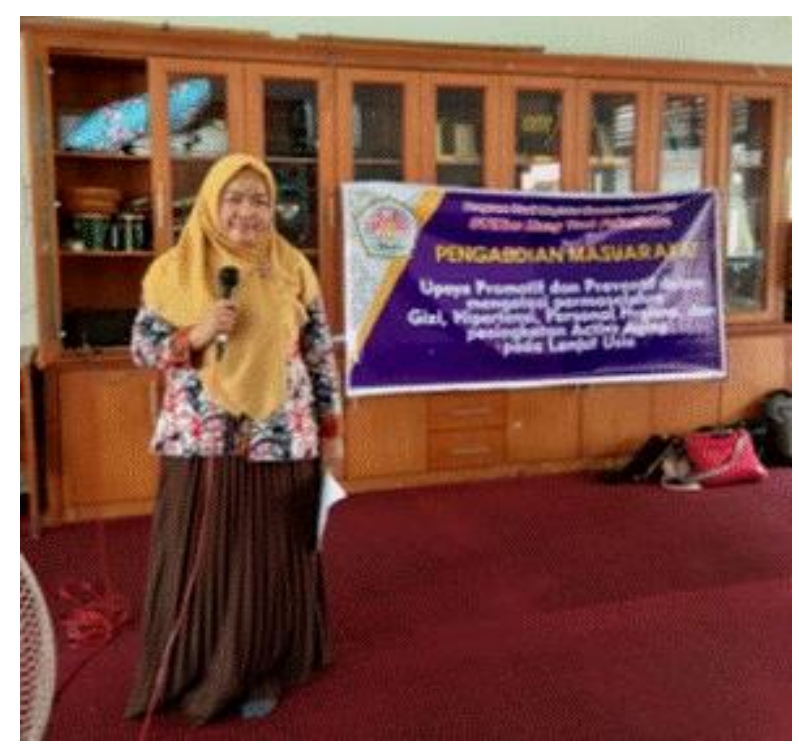

Gambar 3 : Memberikan Penyuluhan mengenai Personal Hygiene.

Dalam penyuluhuhan disampaikan perlunya menjaga kesehatan lansia melalui gerak aktif dan 
berusaha selalu sehat dalam jangka waktu yang lama, menjadi ciri penuaan yang sukses. Lansia akan sukses menjalani masa tuanya dengan perilaku yang sehat (Sabia et al., 2012). Menjaga kebersihan diri dengan kategori tidak baik, masih dijumpai pada sebagian lansia. Lansia sejumlah 53,34\% lansia mempunyai menjaga kebersihan diri yang kurang baik (ZEIN, NUR AINI, 2011).

Presentasi untuk menerangkan perlunya personal hygiene yang dilaksanakan pada lansia akan memberikan manfaat yang sangat berharga bagi perjalanan kehidupan akhir lansia. Lansia yang mempunyai perilaku sehat seperti mempunyai pola makan sehat, tidak merokok, dan melakukan olahraga teratur, dihubungkan dengan memori yang baik dibandingkan yang lebih muda. Sejalan dengan penelitian yang menyatakan tentang perilaku gaya hidup seseorang melindungi kesehatan otak dan menunda timbulnya gejala memori seiring bertambahnya umur (Small et al., 2013).

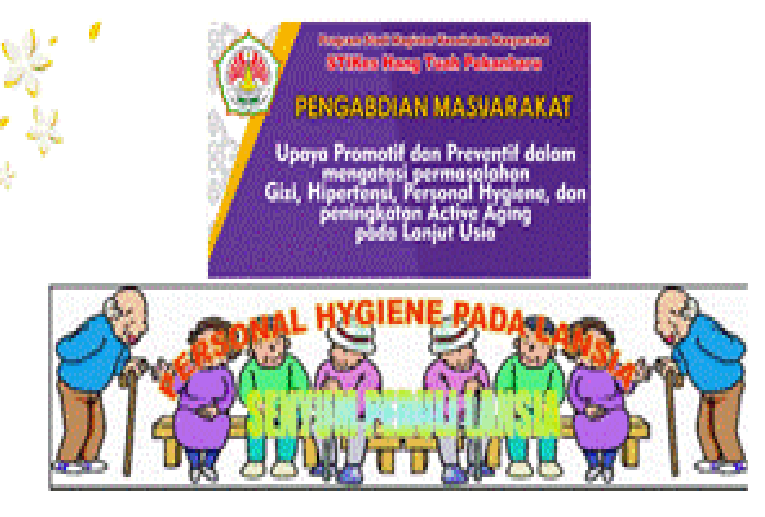

\section{PERSONAL HYGIENE LANSIA}

Gambar 4 : Presentasi mengenai Personal Hygiene

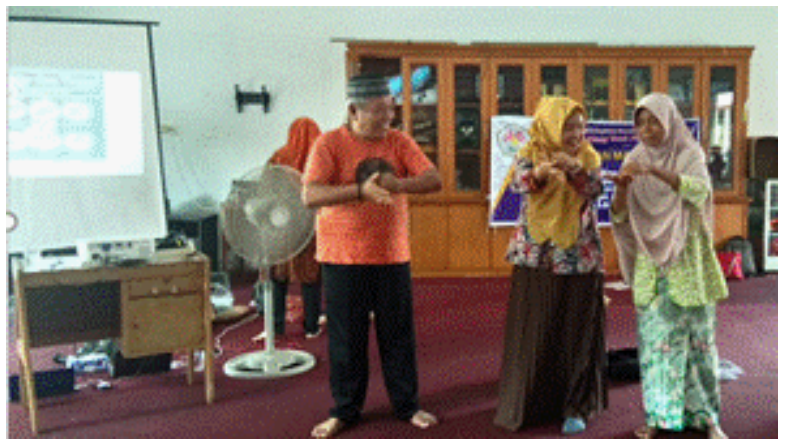

Gambar 5 : Sosialisasi dan Praktek Cuci Tangan Sampai Bersih dengan 5 Langkah.

Lansia membutuhkan pemeliharaan kesehatan, komunikasi aktif, sosialisasi dengan teman, pengembangan intelektual, serta hubungan yang stabil dalam kehidupan. Dan peran keluarga sangat membantu lansia dalam memenuhi kebutuhan dasar tersebut, mencapai kualitas hidup lansia yang baik. Kualitas hidup disini meliputi kesehatan fisik, keadaan psikologis, kemandirian yang baik, hubungan sosial, kepercayaan diri yang sesuai dengan lingkungan tempat tinggalnya (Kelen et al., 2016).

\section{UCAPAN TERIMA KASIH}

Terimakasih kepada Pengurus UPT Pelayanan Sosial Tresna Werdha Husnul Khotimah Kota Pekanbaru yang telah memberi kesempatan sehingga acara bisa berjalan dengan lancar dan juga kepada Ketua Yayasan dan Pimpinan serta LPPM STIKes Hang Tuah Pekanbaru yang telah mendukung baik secara moril dan materil untuk pelaksanaan acara pengabdian masyarakat kepada dosen Magister Ilmu Kesehatan Masyarakat STIKes Hang Tuah Pekanbaru dalam rangka pelaksaan Tridarma Perguruan Tinggi dalam bidang pengabdian masyarakat. Semoga kegiatan ini tetap berlanjut. 


\section{SIMPULAN}

Penyuluhan Personal Hygiene pada Lansia di UPT Pelayanan Sosial Tresna Werdha Husnul Khotimah Kota Pekanbaru berjalan dengan baik dan lancar, meriah dan bersemangat serta mendapat sambutan yang baik dari pengurus dan peserta lansia. Mereka senang mendapatkan perhatian dari masyarakat luar mengenai kegiatan mereka di panti dan juga diberikan informasi mengenai cara mengelola kebersihan pribadi/ personal hygiene. Perilaku hidup sehat dan bersih memang perlu disosialisasikan terus menerus karena kebersihan adalah pangkal kesehatan dan lansia rentan terhadap berbagai penyakit yang berawal dari ketidak bersihan badan. Perawat dan pengurus juga perlu menyadari bahwa mengurus lansia berarti juga mengurus kebersihan mereka.

Diharapkan dengan adanya penyuluhan dari Magister IKMStikes Hang Tuah ini, maka dapat memberikan perhatian terhadap lanjut usia. Diharapkan bisa menjadi program pengabdian masyarakat pada lansia dengan gangguan personal hygiene, serta memberikan motivasi terhadap keluarga/perawat agar mampu merawat keluarga/pasien yang lansia.

\section{DAFTAR PUSTAKA}

Badan Pusat Statistik, Badan Koordinasi Keluarga Berencanan Nasional, Departemen Kesehatan, \& Macro International. (2013). Survei Demografi dan Kesehatan Indonesia 2012. Sdki. https://doi.org/10.1111/j.14710528.2007.01580.x

Fatimah, F. U. D. (2012). MEDIA MEDIKA. 46, 61-68.

Firmana, A. R. (2016). Gambaran Perilaku Hidup Bersih Dan Sehat (PHBS) Pada Lansia Di
Desa Kemukus Kecamatan Gombong Kabupaten Kebumen. Journal of Chemical Information and Modeling, 53(9), 16891699.

https://doi.org/10.1017/CBO9781107415324. 004

Huda, N. of M. M. (2004). TINGKAT KEMANDIRIAN LANSIA DALAM MEMENUHI AKTIVITAS KEHIDUPAN SEHARI-HARI DI BRSD KEPANJEN MALANG. http://eprints.umm.ac.id/18680/

Kelen, A. P. L., Hallis, F., \& Putri, R. M. (2016). Tugas Keluarga Dalam Pemeliharaan Kesehatan Dengan Mekanisme Koping Lansia. Care, 4(1), 58-65.

Permenkes RI No.25, T. 2016. (2016). RENCANA AKSI NASIONAL KESEHATAN LANJUT USIA TAHUN 2016-2019.

Sabia, S., Singh-Manoux, A., Hagger-Johnson, G., Cambois, E., Brunner, E. J., \& Kivimaki, M. (2012). Influence of individual and combined healthy behaviours on successful aging. Canadian Medical Association Journal, 184(18), $1985 \quad$ LP $\quad$ - 1992. https://doi.org/10.1503/cmaj.121080

Small, G. W., Siddarth, P., Ercoli, L. M., Chen, S. T., Merrill, D. A., \& Torres-gil, F. (2013). Healthy behavior and memory self-reports in young, middle-aged, and older adults. February. https://doi.org/10.1017/S1041610213000082

Yuliati, A., Baroya, N., \& Ririanty, M. (2014). Perbedaan Kualitas Hidup Lansia yang Tinggal di Komunitas dengan di Pelayanan Sosial Lanjut Usia (The Different of Quality of Life Among the Elderly who Living at Community and Social Services). Pustaka Kesehatan; Vol 2 No 1 (2014). https://doi.org/http://dx.doi.org/10.33366/cr.v $4 \mathrm{i} 1.474$

ZEIN, NUR AINI, U. O. N. U. S. (2011). GAMBARAN PEMENUHAN KEBUTUHAN PERSONAL HYGIENE PADA LANSIA DI SAMBIROTO $\quad R T \quad 25 \quad R W \quad 04 \quad$ DESA SAMBIBULU TAMAN SIDOARJO. http://repository.unusa.ac.id/id/eprint/3280 
260 Penyuluhan Personal Higyene pada Lanjut Usia di UPT Pelayanan Sosial Tresna Werdha Husnul Khotimah Kota Pekanbaru - Herniwanti, Jasrida Yunita, Endang Purnawati Rahayu, Kiswanto DOI : https://doi.org/10.31004/abdidas.v1i4.55

Zulfitri, R. (2011). Konsep Diri dan Gaya Hidup Lansia yang Mengalami Penyakit Kronis Di Panti Sosial Tresna Werdha (PSTW) Khusnul Khotimah Pekanbaru. Jurnal Ners Indonesia, $1(2), 21-30$. 